\title{
DIÁLOGO ENTRE EDUCAÇÃO, CORPO E ARTES MARCIAIS
}

\author{
Luiz Arthur Nunes da SILVA ${ }^{1}$; Terezinha Petrucia da NÓBREGA ${ }^{2}$; \\ ${ }^{1}$ Doutorando do Programa de Pós-Graduação em Educação/UFRN; E-mail: arthur_nunes@hotmail.com.br \\ ${ }^{2}$ Professora dos Programas de Pós-Graduação de Educação e em Educação Física/UFRN; E-mail: \\ pnobrega68@gmail.com
}

Artigo submetido em março/2015 e aceito em maio/2015

DOI: $10.15628 /$ dialektike.2015.2938

\section{RESUMO}

Trata-se de uma reflexão sobre a educação, o corpo e a filosofia das Artes Marciais no processo de formação do Ser em sua profunda expressão. Ressaltamos as contribuições filosóficas e o engajamento do corpo nessa ação, os princípios filosóficos e a aprendizagem para a vida. O caminho metodológico concerne à fenomenologia, pois trata do espaço vivido que possibilitou reflexão e a possível articulação entre as categorias dessa pesquisa. A interpretação aqui enfocada privilegiou uma reflexão embasada na tradição das Artes Marciais, principalmente no que concerne ao modo como essa transição de experiência se dá por meio da aprendizagem da cultura. Dessa forma, as noções aqui elaboradas permitem refletir sobre a educação e o corpo, e sua capacidade de aprendizagem e de formação por meio das Artes Marciais, vislumbrando a criação de um espaço expressivo no qual se instala o papel desse corpo, da cultura, do legado cultural e dos princípios filosóficos.

PALAVRAS-CHAVE: Artes Marciais; Corpo; Educação; Fenomenologia; Merleau-Ponty.

\section{DIALOGUE AMONG EDUCATION, BODY AND MARTIAL ARTS}

\section{ABSTRACT}

It is a reflection on education, body and philosophy of Martial Arts in the formation of being in its most totalitarian expression. It was analyzed the philosophical contributions and the commitment of the body in this action, the philosophical principles to learning for life. The methodological approach concerns the phenomenology, as its lived space, and promote reflections and the possible connection between the categories of this research. The interpretation focused in this paper favored a reflection based on Martial Arts tradition, mainly concerning the way of how this transition of experience occurs through culture learning. Thus, the concepts developed here allow to reflect on education and body, and its development capacity and its entire formation through Martial Arts, envisioning the creation of a significant space in which settles the role of this body, the culture, the legacy and the philosophical principles.

KEYWORDS: Martial Arts; Body ; Education ; Phenomenology ; Merleau-Ponty. 


\section{JUMBI, SHIJAK! ${ }^{1}$}

Pesquisar é o processo de ir além, de seguir e/ou criar caminhos, de percorrer lugares que por muitas vezes trazem em si, respostas que divergem e convergem ao mesmo tempo em que se complementam. Assim, toda e qualquer pesquisa, estudo ou levantamento, dar-se nessa inquietação pessoal do não contentamento com algo que deveria ser revisto, reavaliado, e dependendo, ressignificado para contemplar a melhoria do mundo de um ou mais sujeitos. Foi assim que o homem evoluiu e é assim que se dá o processo histórico de nossa cultura, nossa sociedade, e também, do desenvolvimento científico.

Nesse mesmo contexto, a ideia que se tem da formação do Ser na sua mais complexa concepção, deve atender as diversas formas que este tem de interagir com o mundo. Pensar nesse sujeito, nesse homem, nesse corpo que a partir das relações entre a emoção, o pensamento e o movimento, interagem ao mesmo tempo em que se desenvolve, é pensar que somos reflexos de nossas próprias ações.

Refletir sobre o corpo, nessa perspectiva, é discorrer nas suas diferentes concepções de entendimento, bem como, as dicotomias que se deparam tentando decifrá-lo. Diversos são os estudos que tentam entendê-lo e, mais ainda são as problemáticas em tentar estudá-lo. Não é de hoje que se realizam estudos a respeito de seu juízo, porém, sua compreensão vai atrelando a cada dia novas perspectivas. Desta forma, passa a ser concebido como elemento primordial da essência dos sujeitos na realidade da vida, que se compõem a partir da interação dos aspectos biológicos, culturais, sociais, históricos, sensíveis, entre outros.

Perante estas novas perspectivas que vêm surgindo sobre o corpo, é importante traçar investigações sobre diferentes aspectos que o englobam, problematizando-o em diferentes esferas e em diferentes propostas. Para que através dessa atividade contínua possamos, talvez, desvendálo em alguns de seus sentidos, em algum dos seus espaços. E é destacando um desses espaços que trazemos a formação do Ser na sua mais completa totalidade, perante essa concepção de corpo. Fala-se aqui, da educação para à vida, privilegiando o sujeito na sua formação integral. E é nessa relação educacional que traçamos reflexões sobre as contribuições filosóficas das Artes Marciais enquanto aporte educativo e seu diálogo direto com este corpo que se movimenta, com toda sua intencionalidade, e se forma como Ser².

Essa pesquisa tem por método o pensamento fenomenológico proposto pelo filósofo Maurice Merleau-Ponty e, através desse caminho foi possível tecer reflexões para articular conceitos que direcionaram nossas ideias às discussões do nosso objetivo aqui proposto, a saber: Quais diálogos podem ser construídos entre educação, corpo e Artes Marciais?

Assim, a fim de atrelar o corpo e a educação em seus significados mais amplos e em sua expressão máxima, já que esse corpo não está somente na educação, mas ele é a educação, recaímos nosso olhar à filosofia das Artes Marciais, norteada pelos princípios éticos,

\footnotetext{
${ }^{1}$ Comando inicial para os lutadores de Artes Marciais coreanas. Significa: "preparar, começar!".

${ }^{2}$ A partir da perspectiva da fenomenologia de Merleau-Ponty, trata-se de compreender a reflexão e a existência como apresentação desse Ser no mundo, onde a expressividade do corpo vivo permite e estabelece expressões existenciais do sujeito encarnado. Assim, nesse movimento, o sujeito e o mundo completam-se, projetando sentidos e ganhando significados onde um caminha ao lado do outro (MERLEAU-PONTY, 2011).
} 
principalmente, e o favorecimento de sua prática para a formação dos sujeitos numa visão integral, situando-o num mundo vivido que quanto mais se conhece, mais se apropria.

\section{A FILOSOFIA DAS ARTES MARCIAIS EM SEU DIÁLOGO COM O CORPO}

O conhecimento histórico que se faz de um objeto de estudo sempre se mostra relevante. No caso do estudo do corpo nas Artes Marciais isso se faz essencial, porque somente ao se conhecer os sentidos e os significados empregados nestes, podemos compreender de forma generalizada sua relação e seu efeito.

A priori, é preciso estabelecer a diferenciação entre Artes Marciais e Lutas, que muitas vezes é compreendida de maneira errônea sendo até empregado em alguns contextos com mesmo significado. Assim, temos que Artes Marciais ${ }^{3}$ são disciplinas físicas e mentais codificadas em diferentes graus, que têm como objetivo principal o desenvolvimento de seus praticantes na sua total integridade. São atividades corporais de ataque e defesa, podendo também - e não somente - ser caracterizadas como lutas (DRIGO, 2005). As Lutas, por sua vez, são práticas que possuem combates diretamente corporais (LOURENZO; SILVA; TEIXEIRA, 2009). A principal diferença entre as duas é que os praticantes de Artes Marciais, principalmente as de origem oriental, consideram que os conteúdos da cultura de origem dessas atividades teriam uma orientação proveniente de uma filosofia de vida.

Desse modo, podemos nos referenciar no contexto dessa pesquisa, ao termo "Artes Marciais", de maneira que tratemos de forma evidenciada os primórdios dessas doutrinas. Pois, trata-se assim, de uma questão de princípios de vida, de uma filosofia.

No que se refere às lutas nas Artes Marciais, é importante atentar que não se tratam de lutas no sentido de uma medíocre contravenção contra um adversário de carne e osso, em confronto direto. Mas, uma luta com fins existenciais, que emanam significados próprios para cada um dos envolvidos e seu mundo vivido. Contudo, não podemos e não devemos abdicar à luta propriamente dita, que faz parte desse processo de aprendizagem nas Artes Marciais. Porém, devemos pensar também qual a significação desse contato direto com outro nas Artes Marciais, trazendo os princípios fundados na criação e no intuito dessas lutas.

Devemos compreender ainda, que nas Artes Marciais, mesmo a questão do "lutar" busca em sua essência original o desenvolver-se com o outro e não contra o outro. Sobretudo, a proposta do caminho da Arte, em seu princípio fundamental, deve ultrapassar as barreiras do local de treino e dar continuidade à vida dos que ali estão envolvidos, pois visa a uma aprendizagem para a vida. Nesse sentido, trazemos o pensamento do Mestre Jigoro Kano ${ }^{4}$ (1860-1938), que criou a arte do

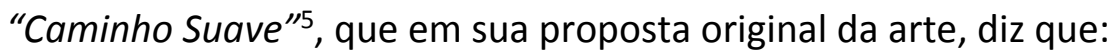

[...] o judô não é apenas uma arte marcial, mas sim um principio básico do comportamento humano. A aplicação desse principio na defesa contra ataques ou

\footnotetext{
${ }^{3}$ O termo Artes Marciais é ocidental, e constitui-se como uma referência às Artes de Guerra, pois sua origem é vinculada ao Deus da guerra greco-romano Marte. Assim, as Artes Marciais segundo esta mitologia são as Artes ensinadas pelo Deus Marte aos homens. As Artes Militares ou Marciais eram todas as práticas utilizadas pelos exércitos no desenvolvimento de treinamento e habilidades para o uso em guerras não importando a origem ou povo que as criou.

${ }^{4}$ Fundador e disseminador da Arte Marcial Judô.

${ }^{5} \mathrm{Ou}$ "Caminho da Suavidade", é a tradução literal e a proposta de Jigoro Kano ao criar o Judô.
} 
como educação física em randori ${ }^{6}$ no dojo é apenas um aspecto do judô - é errado acreditar que o judô termine no dojo (KANO, 2008, p. 66).

A mesma ideia nos apresenta o Mestre Morihei Ueshiba ${ }^{8}$ (1883-1969), quando nos fala sobre o real sentido investido em sua Arte:

O aikido ${ }^{9}$ é o remédio para um mundo doente. Há maldade e desordem no mundo porque as pessoas esqueceram que todas as coisas emanam de uma só fonte. Retorne a essa fonte e deixe para trás os pensamentos egoístas, os desejos mesquinhos e a raiva (STEVENS, 2007, p. 130).

Por vezes, esses ensinamentos e o destino dessa prática oculta de si mesma seus fins, quando pensamos no ensino dessas Artes nos dias de hoje. Porém, não queremos, nem vamos trazer aqui reflexões de conceitos esportivos, pois não é nosso foco, tampouco, o objetivo dessa pesquisa.

Compreendemos que o princípio de aprendizagem que norteia as Artes Marciais baseia-se na construção do Ser na sua maneira mais significativa. E, a verdadeira compreensão dessa Arte, só se torna possível àqueles que se abrem, de coração puro e de desejos que perpassam a lógica da razão. Assim, esse Ser precisa estar, de fato, aberto a aprender, disposto a entrar nessa relação se doando por inteiro.

Sabe-se que, no Oriente essas Artes Marciais apresentam-se ligadas diretamente a outras atividades do cotidiano das pessoas, como a escrita, o cultivo, a jardinagem, a culinária, compondo o modo de vida de seus povos há milênios e sendo amplamente difundida e valorizada (BREDA et al., 2010). Como vemos, as Artes Marciais são parte bastante significativa do legado cultural das civilizações orientais. Muito de seu pensar e agir, em particular, repousa na base comum de toda filosofia das inúmeras Artes Marciais existentes, que buscam o equilíbrio harmonioso em seu contexto mais amplo. Em relação a esse corpo que se mostra nesse contexto social, todavia, Mendes e Nóbrega, reconhecem que:

[...] ao envolver a relação entre corpo, natureza e cultura, configura-se como um conhecimento que vai sendo construído e reconstruído ao longo de nossas vidas e da história. Um conhecimento marcado pela linguagem sensível, que emerge do corpo e é revelada no movimento que é gesto, abarcando os aspectos bioculturais, sociais e históricos, não se resumindo às manifestações de jogos, danças, esportes, ginásticas ou lutas, mas abrangendo as diversas maneiras como o ser humano faz uso do ser corpo, ou seja, como cria e vivencia as técnicas corporais (MENDES; NÓBREGA, 2009, p. 06).

Ao tecermos essa relação teórica proposta por Mendes e Nóbrega (2009), passamos a refletir sobre uma concepção de corpo que busca superar as conhecidas dicotomias, por exemplo, entre corpo e mente, e apontam para uma compreensão de corpo pleno, de historicidade e subjetividade ${ }^{10}$.

\footnotetext{
${ }^{6}$ É um treinamento, uma espécie de luta que não vale nenhum ponto no qual você apenas treina com a pessoa.

${ }^{7}$ Local de muito respeito onde se treinam Artes Marciais, principalmente, as de origens nipônicas.

${ }^{8}$ Fundador e disseminador da Arte Marcial Aikido, que significa "O Caminho Harmonioso da Energia".

${ }^{9}$ Ocidentalmente é compreendido como "O Caminho Harmonioso da Energia".

${ }^{10}$ Merleau-Ponty (2011) reflete esse conceito a partir da constatação de que o homem encontra-se corporalmente inserido no mundo, e que as relações com o outro, com a cultura e com a natureza são mediadas pelo corpo.
} 
Dessa forma, a compreensão de corpo que trazemos aqui para pensar esse corpo em educação nas Artes Marciais advém da concepção adotada por Merleau-Ponty, onde ele nos mostra que o corpo não tem outra maneira de ser corpo se não vivenciando as experiências:

Portanto, sou meu corpo, exatamente da medida em que tenho um saber adquirido e, reciprocamente, meu corpo é como um sujeito natural, como um esboço provisório de meu ser total. Assim, a experiência do corpo próprio opõese ao movimento reflexivo que destaca o objeto do sujeito e o sujeito do objeto, e que nos dá apenas o pensamento do corpo ou o corpo em ideia, e não a experiência do corpo ou o corpo em realidade (MERLEAU-PONTY, 2011, p. 269).

Esse conhecimento encarnado, como nos fala Merleau-Ponty, dá-se a partir da própria experiência em que o corpo não tem outra maneira de se conhecer enquanto corpo senão vivendo. É o próprio corpo criando significações na sua relação primordial com o mundo. Nossos costumes, nossa língua, nossas crenças, a forma como nos comunicamos (verbalmente ou não), nossa linguagem corporal, todo nosso repertório funda-se a partir da relação e das experiências de nosso corpo com o mundo, com o outro e com nós mesmos.

Nas Artes Marciais, traçam-se linhas de significações visando tornar expressiva a educação no corpo. Essas linhas vão estabelecendo nortes e tecendo as raízes da educação neste corpo, por meio das propostas filosóficas que embasam a essência das Artes Marciais. Costumes, crenças, princípios, tudo o que se adquire pela cultura, vai sendo passado por meio da experiência corporal viva das Artes Marciais. E é no movimento desses corpos, na linguagem expressiva e na educação sensível que essa aprendizagem vai se tornando essência à existência desses corpos.

Visto isso, podemos pensar agora sobre as convergências dos princípios que se enraízam nos valores das Artes Marciais, e que são cabíveis de elucidação por tratarem dessa nãodicotomização, ou ainda, fragmentação do corpo, pois encontra-se tecido nesse mundo de significações que vislumbram os caminhos das Artes Marciais. Tais princípios são retratados através da disseminação cultural que passa de geração em geração, e vem repercutindo por milênios através dessa cultura. Achar, então, o ponto chave que norteiam as Artes Marciais, é discorrer a essência das formas que são empregadas para a consolidação dessa educação característica desse contexto, para que se possa refletir esse caráter particular e pessoal de quem a vivencia.

Funakoshi ${ }^{11}$ (1988), ao falar sobre este processo que leva a formação do caráter de um indivíduo envolto na prática da uma Arte Marcial, afirma que:

Se o caminho atrai uma pessoa para percorrê-lo, ele floresce; caso contrário ele definha. O caminho do Karatê pode ser chamado como justiça de um budôn que se manifesta de forma nova e que busca zelosamente pessoas que por ele sigam (FUNAKOSHI, 1988, p. 11-12).

A ideia de restringir nosso foco no sentido do corpo - que aqui se entende como "Eu" em situação com o mundo - dentro das Artes Marciais, significa reforçar a relação de sua vivência e à formação ética do ser humano que está envolta nela, ou seja, vivifica o fator primordial que é a educação.

\footnotetext{
${ }^{11}$ Fundador da Arte Marcial Karatê.

12 São as Artes ou Caminhos Marciais de origem japonesa.
} 
É possível utilizar uma infinidade de ações banais para despertar expressões no corpo, que serão utilizadas em muitos outros contextos, principalmente nas Artes Marciais. Igualmente, podemos pensar de forma significante a maneira inversa: utilizar a educação vivenciada no corpo, pelas Artes Marciais, e que podem estabelecer ligações extremamente significativas no cotidiano. Isso também pode ser compreendido como educação.

Mas de que vivência é esta que estamos falando? Em primeira instância, queremos deixar claro que essa tendência que se tem ao falar de Artes Marciais deve estar muito além do somente descrever movimentos que lhe trarão condição e preparação física. Deve-se entender aqui a vivência, ou prática, de maneira integral: a consolidação do corpo e da mente, da carne e do espírito que agem no mesmo sentido, intensificando sua associação em construção igualitária. Onde, o legado que se é transportado por todos esses séculos, apresentam-se como valores de disciplina, respeito, humildade, cortesia e autocontrole que vingam como filosofia.

Ao refletir sobre essa prática dentro do contexto das Artes Marciais, Santos (2009), afirma que:

[...] quando Jigoro Kano criou o judô ele definiu objetivos para esta arte, que não se limitavam a questões práticas, mas sim um judô que fosse trabalhado como forma de desenvolver o caráter, a moral, autodomínio, autoconhecimento, respeito mútuo, entre outros (SANTOS, 2009, p. 07-08).

Bem como, nos faz referência Nóbrega (2008), quando nos diz que:

Como consequência, não há somente uma forma de aprender ou mesmo uma coisa ou um conjunto definido de coisas a serem aprendidas. Podemos aprender diferentes coisas em uma mesma situação educativa (NÓBREGA, 2008, p. 399).

Com base nessa concepção, Jigoro Kano, segundo Virgílio (1994), propõe através dos fundamentos que lhe propiciaram a formação do "caminho suave"13, que esta prática, ou vivência, tivesse sua filosofia voltada no sentido do aperfeiçoamento moral, ético e espiritual, além de físico e intelectual, preconizando a Paidéia ${ }^{14}$, ou seja, a formação integral do ser humano. Para ele, a prática da Arte Marcial deveria propiciar o desenvolvimento do caráter do indivíduo, de forma a compreender toda a ação global da intencionalidade que ali se faz presente.

Assim, como afirma Mendes e Nóbrega (2004):

[...] a intencionalidade dos gestos expressa a maneira única de existir no ato do momento vivido, uma vez que o corpo humano, por estar atado ao mundo através de uma relação dinâmica, atribui sentidos que se renovam conforme a situação (MENDES; NÓBREGA, 2004, p. 130).

Ou seja, deve-se entender que todo corpo que se movimenta expressa desejos, sentidos, significados únicos, referentes a quem os realiza. Neste sentido, devemos entender o corpo, nas Artes Marciais, como um corpo que age, aprende, se educa, ensina e expressa sentimentos, um objeto pluralizado e que atrela todos os significados que Ihe foi lapidado.

Ainda, para Merleau-Ponty (2011), este corpo deve ser entendido como:

\footnotetext{
${ }^{13}$ Tradução literal para a Arte Marcial Judô.

${ }^{14}$ Processo de educação em sua forma verdadeira, sua forma natural e genuinamente humana.
} 
[...] um conjunto de significações vividas que caminha para seu equilíbrio. Por vezes forma-se um novo nó de significações: nossos movimentos antigos integram-se a uma nova entidade motora [...] repentinamente nossos poderes naturais vão ao encontro de uma significação mais rica que até então estava apenas indicada em nosso campo perceptivo ou prático, só se anunciava em nossa experiência por uma certa falta, e cujo advento reorganiza subitamente nosso equilíbrio e preenche nossa expectativa cega (MERLEAU-PONTY, 2011, p. 212).

Dessa forma, dialogando com os estudos de corpo e a filosofia das Artes Marciais, passamos a entendê-los sobre novos olhares, sobre o viés da educação. Ao pensarmos sobre o corpo devemos compreendê-lo como aspecto primordial da existência humana, já que ele "é a medida da nossa existência no mundo". Além disso, "o corpo não é uma coisa, nem ideia, o corpo é movimento, gesto, linguagem, sensibilidade, desejo, historicidade e expressão criadora". Assim, concebemos que o corpo é um múltiplo de dimensões que não se fragmentam, mas, ao contrário, se complementam para caracterizar cada sujeito (NÓBREGA, 2010, p. 15-47).

Cada momento do tempo, segundo sua própria essência, põe uma existência viva e intemporal na construção do Ser. Essas experiências encarnam e contemplam o Ser em sua maneira puramente verdadeira, e é possível evocá-las sem precisar pedir autorização a nenhum dos outros tempos, seja passado, presente ou futuro. Essas experiências adquiridas são, da mesma forma que sou meu corpo. Elas não estão ali para mim, eu sou assim por elas me serem.

Enquanto sou corpo, engajo-me entre as coisas, e atrelo significações a elas. Minha experiência a partir da presença corporal fazem as coisas existirem para mim enquanto sujeito encarnado, o que torna comum que haja uma educação proveniente dessa relação deste corpo, fundado aqui, nos princípios das Artes Marciais.

As Artes Marciais ampliam os conceitos de educação expressiva do Ser. Uma educação para a vida. E apresenta elementos significativos para compreender a aprendizagem que se desenrolam durante o tempo, durante o caminho, e se desenvolve a partir do movimento que atrelam acontecimentos e significações ao corpo.

Esses corpos nas Artes Marciais, não expressam somente e tão somente movimentos direcionados com um objetivo único. É gesto, ao mesmo tempo em que é expressão, ao mesmo tempo em que é movimento, é educação. É sutil, é belo, é harmônico, é tradição. Também é doloroso, é árduo e trabalhoso. Trata-se de uma dialética de compreender o corpo e o movimento nas Artes Marciais, a partir de uma lógica recursiva em que as ações são complementares, mas, que este corpo em movimento é o ser-no-mundo capaz de aprender as coisas do mundo de forma a trazer sentidos e significados a partir de uma educação sensível.

Sentir e compreender constituem-se em um mesmo ato de significação, possíveis pela nossa condição corpórea e pelo acontecimento do gesto, cuja estesia inaugura a possibilidade de uma racionalidade que emerge do corpo e de seus sentidos biológicos, afetivos, sociais, históricos. Essa compreensão é significativa para redimensionar o fenômeno do conhecimento, relacionando-o à experiência vivida, ao corpo e aos sentidos (NÓBREGA, 2008, p.148).

A vivência nas Arte Marcial e seus princípios filosóficos enquanto educação e formação do Ser está colocada como campo de possibilidades para a educação do sensível, e enaltece o sentido dessa educação como fator primordial para esse acontecimento que se dá no corpo, na carne. 
Sendo assim, deve-se pensar neste corpo, que está envolto nessa educação que o reafirma enquanto Ser, de maneira incompleta e inacabada. $E$, que, por ser inacabado, encontra-se em constante vivência e convivência com o mundo e com o outro, sempre fazendo parte dessa essência de mudanças, de aprendizagem, de sentidos e de significados que vão se atrelando e tomando partes nessa ação (MEDEIROS, 2010).

Dessa forma, pensar nas Artes Marciais enquanto aporte filosófico para a formação do indivíduo, aqui pensado no âmbito da educação e do corpo, é deixar-se levar pela obra de um legado que há séculos existe e que permeia toda a vida de seus disseminadores, professores e alunos, Mestres e Discípulos. Pensando assim, a formação integral do Ser aprofunda-se em seus princípios e valores, permitindo que este elabore e reconheça as estruturas que alicerçam toda a fundamentação que norteiam a prática das Artes Marciais, passando a configurar-se não somente como uma prática desgarrada de seus valores, mas se representando como principio fundamental para sua formação e para a vida.

\section{KUMAN, SHIÔ!15}

Com base no que foi exposto, evidenciamos que a compreensão de corpo nas Artes Marciais sempre esteve permeada de inscrições que são fundamentais para a formação deste indivíduo que a vivencia. Esses elementos vão se configurando a partir dos sentidos e significados únicos na medida em que cada corpo se apresenta disposto e aberto a sua inserção.

Ao percebermos que a educação, o corpo e as Artes Marciais se interpenetram através de uma lógica recursiva, compreendemos que nesta ação esse corpo é passivo ao mesmo tempo em que é ativo, pois, na medida em que apreende, expressa, desenvolve-se e ensina. Trazendo à tona as reflexões feitas nesta pesquisa, pensamos que a formação do Ser, ao considerar o corpo em sua construção totalitária, é capaz de se desenvolver a partir dos caminhos filosóficos das Artes Marciais e, a posteriori, passar esses ensinamentos a outrem, a partir de uma educação sensível.

Em síntese, devemos entender que as Artes Marciais devido à sua filosofia de vida, formam um grupo extremamente vasto de sentidos e significados únicos e multilaterais, com práticas e valores milenares, por isso mesmo tem grande potencial educativo. Nesse caso, o importante é notar que, apesar de existir diversas filosofias, grande parte, efetivamente, converge para o mundo de princípios igualitários, de disciplina, comprometimento com o outro e com a vida, formação do caráter educativo mediado pela moral e pela ética, respeito, humildade e integridade. Dessa forma, desembocamos numa perspectiva no trato de construção do caráter do ser humano, na sua mais ampla possibilidade de existência e na mais complexa forma de criação, pensando assim numa educação para a vida.

\section{REFERÊNCIAS}

BREDA, M. et al. Pedagogia do esporte aplicada às lutas. São Paulo: Phorte, 2010. FUNAKOSHI, G. Karate-do Nyumon: texto introdutório do mestre. São Paulo: Cultrix, 1988. KANO, Jigoro. Energia mental e física: escritos do fundador do judô. São Paulo: Pensamento, 2008.

${ }^{15}$ Comando final para os lutadores de Artes Marciais coreanas. Significa: "parar, descansar". 
LOURENZO, E.; SILVA, F.; TEIXERA, S. O ensino de lutas na Educação Física: construindo estruturantes e mudando sentidos. 2009. (<http://wwwfundacaohantipoff.mg.gov.br/pdf/tabloidelutasedfisica.pdf $>$ ). (Acesso em 15 mar. 2009).

MEDEIROS, R. M. N. Uma educação tecida no corpo. São Paulo: Editora Annablume, 2010.

MENDES, Maria Isabel Brandão de Souza; NÓBREGA, Terezinha Petrúcia. Corpo, natureza e cultura: contribuições para a educação. Revista Brasileira de Educação. № 27, p. 125-137, set/out/nov/dez, 2004.

Cultura de movimento: reflexões a partir da relação entre corpo, natureza e cultura. Rev. Pensar a prática, vol. 12, no 2, p. 1-10, maio/ago. 2009.

MERLEAU-PONTY, Maurice. Fenomenologia da percepção. 4. ed. Trad. Carlos Alberto Ribeiro de Moura. São Paulo: WMF Martins Fontes, 2011.

NOBREGA, Terezinha Petrúcia. Uma fenomenologia do corpo. São Paulo: Editora Livraria da Física, 2010. Merleau-Ponty: o corpo como obra de arte. Cronos, Natal-RN, vol. 9, no 2, p. 393-403, jul./dez.

2008.

SANTOS, S. H. S. M. Características sociais do judô na escola. 2009, p. 7-8. (<http://www.fpj.com.br/artigos/2009_artigo_csje.pdf>). (Acesso em 17 out. 2010).

STEVENS, John. Três mestres do budo: Kano (judô), Funakoshi (karatêUeshiba (aikido). Tradução de Luiz Carlos Cintra. São Paulo: Cultrix, 2007.

VIRGILIO, S. A Arte do Judô. 3. ed. Porto Alegre: Rigel, 1994. 